\title{
Does International Mobility of High-Skilled Workers Aggravate Between-Country Inequality?*
}

\author{
Volker Grossmann ${ }^{\dagger}$ and David Stadelmann ${ }^{\ddagger}$
}

April 23, 2010

\begin{abstract}
This paper analyzes the interaction of international migration of high-skilled labor and relative wage income between source and destination economies of expatriates. We develop an overlapping-generations model with increasing returns which suggests that international integration of the market for skilled labor aggravates between-country inequality by harming those which are source economies to begin with while benefiting host economies. The result is robust to allowing governments to optimally adjust productivity-enhancing investments which could potentially attenuate brain drain. Optimal public investment tends to decrease in response to higher emigration.
\end{abstract}

Key words: Brain drain; Between-country wage differences; Public investment; Total factor productivity.

JEL classification: F22; O30; H40.

${ }^{*}$ Acknowledgements: We are indebted to the editor, Gordon Hanson, and two anonymous referees for substantially improving the paper. We are also grateful to Michel Beine, Bruno S. Frey, Hillel Rapoport, Avi Simhon, and John Wilson for comments and suggestions on an earlier draft. We also benefited from discussion with seminar participants at the Ben-Gurion University of the Negev, University of Zurich, University of Geneva, University of Fribourg, University of Siegen, the Annual Meeting of the European Economic Association 2008 in Milan, the conference "Globalization and the Brain Drain. Theory, Evidence and Policy" (December 2008) in Jerusalem and Ramat Gan, and the Annual Meeting of the German Economic Association 2009 in Magdeburg.

$\dagger$ University of Fribourg; CESifo, Munich; and Institute for the Study of Labor (IZA), Bonn. Postal adress: University of Fribourg, Departement of Economics, Bd. de Pérolles 90, G424, 1700 Fribourg, Switzerland. Tel.: +41 (026) 3009383. Email: volker.grossmann@unifr.ch

$\ddagger$ University of Fribourg, Departement of Economics, Bd. de Pérolles 90, F410, 1700 Fribourg, Switzerland. Tel.: +41 (026) 3009382. Email: david.stadelmann@unifr.ch 


\section{Introduction}

In the year 2000, 20.4 million tertiary educated immigrants lived in OECD countries, up from about 12.5 million in the year 1990 (Docquier and Marfouk, 2006). Half of the skilled migrants resided in the US and about a quarter in other Anglo-Saxon countries. Liberalization of international labor markets continues, particularly for high-skilled workers. New regulation in developed countries, such as the "blue card" scheme adopted by the Council of Europe in May 2009, tends to reduce immigration barriers for high-skilled labor. Thus, the outflow of skilled individuals from developing countries may further increase in the near future. The European Commission has also raised concerns, however, that high-skilled emigration could harm developing regions which are already suffering from brain drain such as the Caribbean, Central America and Sub-Saharan Africa.

This paper examines the impact of increasing mobility of high-skilled workers on international migration and relative wage income between source and destination economies of expatriates. At the same time, we account for the fact that cross-country differences in wages for skilled workers are an important determinant of high-skilled migration in the first place (e.g., Lucas, 2005; Grogger and Hanson, 2008). Thus, we focus on the dynamic interaction of between-country wage differences for the skilled and brain drain from poor to rich countries. We develop an overlapping-generations model with endogenous educational and locational choice of individuals, where brain drain has detrimental effects on total factor productivity (TFP) in an economy. Declining mobility costs for high-skilled workers lead to further emigration which reduces TFP in countries already facing brain drain. Consequently, and contrary to conventional wisdom from standard (one-sector) models, even skilled workers in source countries lose. Thus, our model suggests that income differences for skilled labor across countries and between-country income inequality widen in response to increased migration of skilled workers.

Source countries may respond with different policies to mitigate brain drain if advanced economies open up their labor markets for skilled migrants. In view of our focus on the effects of high-skilled migration on productivity differences across countries, we ask whether source countries should try to attenuate brain drain by raising public 
expenditure for productivity-enhancing measures, like publicly financed investments in infrastructure or basic education. ${ }^{1}$ Our analysis on the optimal policy response of source countries suggests that developing countries may not want to implement such a policy change to mitigate the brain drain problem. We argue that, from the perspective of non-migrants in source economies, it rather tends to be optimal that public investment expenditure is reduced if international labor markets for skilled workers further integrate. The result may hold true even if governments can run public deficits to finance public investment. $^{2}$ In any case, the analysis again suggests that declining mobility costs do not only trigger emigration in source economies. They also fuel future emigration pressure, by reducing wage income even for skilled non-migrants. Thus, our main result is robust to allowing for endogenous public investment responses. ${ }^{3}$

In line with seminal papers on brain drain like Bhagwati and Hamada (1974), we emphasize adverse effects of outward migration for the source economy. In contrast to this earlier literature, we focus on the dynamic interaction between emigration and between-country inequality through adverse productivity effects of brain drain. More recently, scholars pointed to potential brain gain effects for the sending country (e.g., Mountford, 1997; Stark, Helmenstein and Prskawetz, 1997, 1998; Beine, Docquier and Rapoport, 2001). They show that if emigration prospects of skilled workers in developing countries are uncertain due to immigration quotas in advanced countries, a higher quota (better emigration prospect) fosters incentives to acquire education. The drain effect from higher outflows may then be dominated by an increase in the domestic skilled labor force. While not denying this possibility, our theoretical analysis does not emphasize such a mechanism. ${ }^{4}$ We also abstract from potential gains for source economies from

\footnotetext{
${ }^{1}$ Justman and Thisse $(1997,2000)$ examine the implications of increasing mobility of high-skilled labor on publicly financed higher education. They analyze a non-cooperative game between two symmetric, advanced countries. In contrast, we assume that (higher) education is private and focus on the perspective of a developing country which faces brain drain to a more advanced country.

${ }^{2}$ The result is not due to a decrease in the tax base stemming from additional outflows. It also holds if individuals are forced to pay taxes in their country of birth, irrespective of their residency. In the present paper, we examine the optimal government response as a robustness check for our main results.

${ }^{3}$ Grossmann and Stadelmann (2009) provide empirical evidence for a negative impact of higher emigration rates of skilled workers on public investment.

${ }^{4}$ In our model, migration possibilities are known ex ante to individuals and taken into account in the education decision. However, there is no explicit immigration quota, albeit there exist migration costs. In fact, the empirical relevance of a potential brain gain mechanism seems to be confined to
} 
remittances since we are interested in first-order effects of migration flows of high-skilled workers on market incomes.

Our paper may be most closely related to Miyagiwa (1991) and Mountford and Rapoport (2007). Miyagiwa (1991) aims to explain why countries like the US can pay high wages to skilled professionals and therefore attract the best immigrants from abroad. He assumes that there are increasing returns to education, which implies that the wage level of educated workers rises with the amount of skilled labor. In contrast, we endogenously derive effects of migration on TFP by borrowing from increasing-returns frameworks common in endogenous growth and new trade theory. Mountford and Rapoport (2007) analyze the interaction between migration flows, human capital formation in the presence of human capital externalities, and fertility. In their model population size increases in poor countries which suffer from brain drain due to fertility responses. Consequently, between-country inequality is predicted to rise in the longer run for a very different reason than in our model.

There is a large literature on potential wage effects of immigration (surveys are provided by Borjas, 1994, and Card, 2009). The effects seem generally to be negative and of small magnitude if all immigrants are considered. According to Borjas (2003), immigrants with college degree, contrary to conventional wisdom, may have a positive, albeit again a small impact on wages for college-educated natives in the US. Dustmann, Fabbri and Preston (2005) report for the UK that the effects of high-skilled immigration on wages is, if anything, positive. In a similar vein, Friedberg (2001) shows that native wages rise when immigrants enter high-skilled occupations in the Israeli labor market. Our theory is consistent with such empirical evidence on wage effects of high-skilled migration.

The remainder of this paper is organized as follows. Section 2 presents the basic model. Section 3 analyzes the relationship between emigration and relative wage income between source and destination. Section 4 extends the basic model to account for an optimal adjustment of public investment. Section 5 provides concluding remarks.

poor countries with rather low levels of human capital and low emigration rates of the skilled (Beine, Docquier and Rapoport, 2001, 2008). 


\section{The Basic Model}

Consider a small overlapping generations economy. Individuals live two periods and are endowed with one unit of time. Each period, a unit mass of individuals is born. In the first period of life, each individual decides whether to become high-skilled, which requires $e \in(0,1)$ units of time, or to remain low-skilled. High-skilled individuals may emigrate at some cost which may differ among individuals. In order to focus on migration patterns of high-skilled workers, we assume that low-skilled labor is immobile. ${ }^{5}$ Time not used for education is inelastically supplied to a perfect labor market. Individuals may also save (or borrow) freely in an international financial market at an exogenous world market interest rate, $r$. In the second period of life, individuals retire and live off their savings.

Let $c_{t, y}(i)$ and $c_{t+1, o}(i)$ denote the consumption level of a homogenous final good of individual $i$ in period $t=1,2, \ldots$ (when young) and $t+1$ (when old), respectively. Preferences are represented by the intertemporal utility function

$$
U_{t}(i)=\log \tilde{c}_{t, y}(i)+\rho \log \tilde{c}_{t+1, o}(i)
$$

with discount factor $\rho \in(0,1)$, where

$$
\tilde{c}_{y}(i)=\left\{\begin{array}{c}
c_{y}(i) \text { if } i \text { does not migrate } \\
\frac{c_{y}(i)}{1+\theta(i)} \text { if } i \text { migrates; }
\end{array}\right.
$$

the definition for $\tilde{c}_{o}(i)$ is analogous. ${ }^{6}$ That is, if an individual chooses to work abroad, the consumption level is discounted in both periods. ${ }^{7}$ Parameter $\theta(i)$ captures, for instance, individual-specific costs of living in a foreign social environment and the treatment of foreigners by administrative bodies. It is known to individuals ex-ante. It is distributed according to a continuous p.d.f. $\varphi(\theta)$, with support $\Theta$, where $\inf \Theta \geq 0$. The c.d.f. of $\theta$ is denoted by $\Phi(\theta)$. It turns out that in order to avoid the possibility of multiple long-run

\footnotetext{
${ }^{5}$ This can be motivated by the fact that migration costs are higher for people with lower education as they are more likely to have difficulties in finding a job, learning a foreign language and integrating in the foreign society. Furthermore, institutional barriers in potential host economies may prevent migration of low-skilled workers.

${ }^{6}$ Time index $t$ is omitted whenever this does not lead to confusion.

${ }^{7}$ For a similar way of modelling migration costs, see Stark, Helmenstein and Prskawetz (1997).
} 
equilibria, it is sufficient (but not necessary) to assume that

$$
\varphi^{\prime}(\theta) \geq 0 \text { for all } \theta \in \Theta \text {. }
$$

When deciding whether or not to become skilled, individuals take both migration incentives and costs into account. The disposable wage income in $t$ of a skilled migrant abroad (net of possible taxes in the destination country and a possible emigration tax) is exogenously given by $\bar{y}_{t}$.

The final good is chosen as numeraire. In $t$, output $Y_{t}$ is produced under perfect competition, according to the technology

$$
Y_{t}=\left(X_{t}\right)^{\alpha}\left(A_{t} H_{Y, t}\right)^{\beta}\left(A_{t} L_{Y, t}\right)^{1-\alpha-\beta}
$$

$\alpha, \beta \in(0,1) . H_{Y}$ and $L_{Y}$ is the high-skilled and low-skilled labor input, respectively, $A$ measures the efficiency of labor, and $X$ denotes the input of a manufactured (composite) capital good.

There is a perfectly competitive sector which produces the capital good by combining $n$ intermediate inputs according to the CES-production function

$$
X_{t}=\left[\int_{0}^{n_{t-1}} x_{t-1}(j)^{\alpha} d j\right]^{\frac{1}{\alpha}}
$$

where $x(j)$ denotes the quantity of the intermediate input produced in sector $j \in[0, n]{ }^{8}$ The time lag of one period in the input-output relationship (4) captures that the capital good has to be produced in advance of using it as an input in the final goods sector. As in endogenous growth theory and new trade theory, each intermediate input $j$ is produced by a monopolistic firm. Intermediate goods producers can transform one unit of foregone consumption into one unit of output, i.e., the marginal cost is equal to the interest rate $r$. There is a large number of potential intermediate goods producers in the economy. Entry is free but requires a fixed amount of $f>0$ units of skilled labor (e.g.

\footnotetext{
${ }^{8}$ According to (3) and (4), there are constant-returns to scale in the production of both the final good and the capital good.
} 
adminstrative and managerial overhead requirement) each period. ${ }^{9}$ The number of firms in $t \geq 1, n_{t}$, is endogenously determined via free entry, whereas $n_{0}>0$ is given.

For a given amount of resources employed in production, TFP is increasing in $n$. To see this, consider an equilibrium where all firms produce the same amount, $x(j)=x$ (which will be shown to hold). The economy's "capital stock" is given by $K \equiv n x$. Thus, we have $Y=B K^{\alpha}\left(H_{Y}\right)^{\beta}\left(L_{Y}\right)^{1-\alpha-\beta}$, where TFP is given by $B \equiv(A n)^{1-\alpha}$ and increasing in $n$. In other words, since the marginal productivity of each intermediate good is declining, an increase in the number of intermediate goods leads to specialization gains which in turn boost TFP. This mechanism has been emphasized by monopolistic competition models in new trade theory (e.g., Ethier, 1982) and endogenous growth theory (e.g., Romer, 1990). It is adopted here to endogenize adverse productivity effects of brain drain in the source economy.

The measure $A$ for the efficiency of labor is held constant in the basic model. In section 4, we extend the analysis to examine if the main insights change if (benevolent) national governments can react to declining mobility costs (and possibly larger migration flows), by raising public investment, which in turn affects $A$. We will assume that public investment is financed by proportional income taxation. For the moment, suppose the income tax rate in each period, $\tau_{t} \in[0,1)$, is exogenous. ${ }^{10}$

\section{Equilibrium Analysis}

In this section we analyze the equilibrium from a developing country's perspective which will face brain drain in equilibrium. Immigration could be treated analogously, but is not considered here for the sake of brevity (see Grossmann and Stadelmann, 2008, for a way this can be done).

An individual $i$ with disposable income $y_{t}(i)$ in the first period of life, $t$, maximizes

\footnotetext{
${ }^{9}$ Assuming instead that the labor requirement is partly or exclusively in terms of low-skilled labor is inconsequential for the main results.

${ }^{10}$ We may assume that the tax revenue is spent for a public good which enters the utility function in an additive fashion. In this case, public good consumption does not affect any decision.
} 
intertemporal utility (1) subject to the constraint

$$
c_{t+1, o}(i)=(1+r)\left[y_{t}(i)-c_{t, y}(i)\right] .
$$

Observing the definition of $\tilde{c}_{t, y}(i)$ and $\tilde{c}_{t+1, o}(i)$, it is easy to show that this leads to the indirect utility function

$$
U_{t}(i)=\left\{\begin{array}{c}
(1+\rho) \log y_{t}(i)+b \equiv v\left(y_{t}(i)\right) \text { if } i \text { does not migrate } \\
(1+\rho) \log \left(\frac{y_{t}(i)}{1+\theta(i)}\right)+b \text { if } i \text { migrates }
\end{array}\right.
$$

where $b \equiv \rho \log [\rho(1+r)]-(1+\rho) \log (1+\rho)$ is an unessential constant.

In equilibrium, as all workers have the same time costs $e$ to acquire education, net wage income for high-skilled and low-skilled workers must be proportional in the domestic economy. ${ }^{11}$ Formally, denoting by $w_{H}$ and $w_{L}$ the gross wage rate for high-skilled and low-skilled labor, respectively, in equilibrium we have

$$
w_{H}(1-e)=w_{L}
$$

The capital goods sector maximizes the present discounted value (PDV) of profits. In period $t-1$, it solves

$$
\max _{X_{t},\left\{x_{t-1}(j)\right\}_{0}^{n_{t-1}}}\left\{\frac{P_{t} X_{t}}{1+r}-\int_{0}^{n_{t-1}} p_{t-1}(j) x_{t-1}(j) d j\right\} \text { s.t. (4), }
$$

taking the price of the capital good, $P$, as well as intermediate input prices, $p(j), j \in$ $[0, n]$, as given. The first-order conditions and the fact that $P$ equals the marginal product of the capital good, $\alpha Y / X$, implies the following inverse demand function for

\footnotetext{
${ }^{11}$ The assumption that time costs to become skilled are identical across individuals is made for simplicity and does not affect the main results of this paper. However, as a result of heterogeneity in education costs, brain drain would have effects on domestic wage inequality. Such effects would also arise if the number of skilled and unskilled workers were exogenous. Modeling the education decision intends to take a longer run view. This is natural in our context where we emphasize productivity effects of brain drain. See, for instance, Yabuuchi and Chaudhuri (2007) for a theoretical analysis of the effects of migration on domestic wage inequality when education levels are exogenous.
} 
intermediate input $j$ :

$$
p_{t-1}(j)=\frac{\alpha}{1+r} \frac{Y_{t}}{\left(X_{t}\right)^{\alpha}} x_{t-1}(j)^{\alpha-1}
$$

Recalling that intermediate input firms have marginal cost $r$, profits (sales revenue minus production costs minus fixed costs) of firm $j$ in $t-1$ are given by

$$
\pi_{t-1}(j)=\max _{p_{t-1}(j), x_{t-1}(j)}\left\{\left(p_{t-1}(j)-r\right) x_{t-1}(j)-w_{H, t-1} f\right\} \quad \text { s.t. } \quad(9)
$$

It is easy to show that prices are set according to $p_{t-1}(j)=r / \alpha$.

In equilibrium, due to free entry, the zero-profit condition $\pi_{t-1}(j)=0$ for all $j$ and $t$ must hold. Finally, labor markets must clear. Denote the total number of skilled and unskilled natives by $H$ and $L$, respectively, i.e., $H+L=1$, and the mass of skilled emigrants by $m$. $H, L$ and $m$ are endogenously determined.

The labor market clearing conditions read ${ }^{12}$

$$
\begin{aligned}
L_{Y} & =L \\
H_{Y}+n f & =(1-e)(H-m) .
\end{aligned}
$$

Moreover, disposable income $y(i)$ of a skilled non-migrant is $w_{H}^{\text {net }} \equiv(1-\tau) w_{H}$ whereas emigrants earn $\bar{y}$ abroad. Thus, according to indirect utility function (6), a skilled worker $i$ migrates if and only if $\bar{y} \geq(1+\theta(i)) w_{H}^{\text {net }}$. This condition can be rewritten as $\theta(i) \leq \bar{y} / w_{H}^{\text {net }}-1$. Thus, if $\bar{y} \geq w_{H}^{\text {net }}$, the number of emigrants is given by

$$
m=\Phi\left(\frac{\bar{y}}{w_{H}^{n e t}}-1\right)
$$

Making use of equilibrium conditions and derived relationships we find that the following result holds:

\footnotetext{
${ }^{12}$ Recall that there are $H_{Y}$ skilled workers in the final goods sector and each of the $n$ intermediate good firms employs $f$ skilled workers. Also recall that skilled individuals work only a fraction $1-e$ of their time and that there are $H-m$ skilled workers remaining in the economy after emigration.
} 
Lemma 1. In equilibrium, the wage rate for skilled labor is given by

$$
w_{H, t}=\gamma A_{t} n_{t-1}
$$

$\gamma \equiv \beta^{\frac{\beta}{1-\alpha}}\left(\frac{1-\alpha-\beta}{1-e}\right)^{\frac{1-\alpha-\beta}{1-\alpha}}\left(\frac{\alpha^{2}}{(1+r) r}\right)^{\frac{\alpha}{1-\alpha}}$. The number of intermediate good firms evolves according to the first-order difference equation

$$
n_{t}=\frac{1-e}{f}\left[1-\Phi\left(\frac{\bar{y}_{t}}{\left(1-\tau_{t}\right) \gamma A_{t} n_{t-1}}-1\right)\right]-\frac{1+r}{\alpha} n_{t-1} \equiv Z\left(n_{t-1}\right)
$$

We have $Z(0)=0, \lim _{n \rightarrow 0} Z^{\prime}(n) \rightarrow \infty, \lim _{n \rightarrow \infty} Z^{\prime}(n)<0$ and, under assumption $(A 1), Z^{\prime \prime}(n)<$ 0 . The number of firms in $t-1, n_{t-1}$, is negatively associated with the number of emigrants in $t$ :

$$
m_{t}=\Phi\left(\frac{\bar{y}_{t}}{\left(1-\tau_{t}\right) \gamma A_{t} n_{t-1}}-1\right)
$$

All proofs are relegated to an on-line appendix. ${ }^{13}$

Wage rates positively depend on the number of firms, $n$, due to specialization gains which arise if more intermediate goods are available, as discussed above. The model thus proposes a novel microfoundation for the notion that brain drain reduces productivity in an economy. The mechanism runs through the adverse effects of brain drain on the number of founded firms.

We now make use of Lemma 1 to examine the impact of a decrease in mobility costs (further international integration of the market for skilled labor) on emigration, the number of intermediate good firms, TFP, and wages. A decrease in mobility costs is defined as a shift in the c.d.f. of $\theta$, from $\Phi_{0}(\theta)$ to $\Phi_{1}(\theta)$, such that $\Phi_{1}(\theta)>\Phi_{0}(\theta)$ for all $\theta$ in the interior of support $\Theta$ (i.e., $\Phi_{0}(\theta)$ first-order stochastically dominates $\Phi_{1}(\theta)$ ). In words: for any given $\theta$, the share of individuals with mobility costs higher than $\theta$ declines and the share of individuals with costs lower than $\theta$ increases. This leads to the main result of this paper.

Proposition 1. Suppose that $\xi \equiv \frac{\bar{y}_{t}}{\left(1-\tau_{t}\right) \gamma A_{t}}$ is time-invariant and (A1) holds. ${ }^{14}$

\footnotetext{
${ }^{13}$ Stable link: http://www.unifr.ch/makro/assets/files/publications/Proofs_BD_JDE.pdf

${ }^{14}$ For instance, $\xi$ is time-invariant if the tax rate $\tau$ is time invariant and net income abroad, $\bar{y}$, grows
} 
Then:

(i) There is a single interior steady state equilibrium value for the number of firms, $n^{*}$.

(ii) If mobility costs decline, the steady state value of both the number of firms $\left(n^{*}\right)$ and the wage rate for skilled labor $\left(w_{H}^{*}=\gamma A n^{*}\right)$ decreases, whereas the steady state number of emigrants $\left(m^{*}=\Phi\left(\xi / n^{*}-1\right)\right)$ increases.

(iii) If the economy was initially in steady state, then $w_{H}$ declines and $m$ rises also in the subsequent period after labor markets integrate.

\section{$<$ Figure $1>$}

Fig. 1 graphically illustrates the impact of a decrease in mobility costs on the evolution of the number of firms when the economy is initially in steady state equilibrium. A decline in mobility costs implies a shift of function $Z$ from $Z_{0}$ to $Z_{1}$. We distinguish two cases in which the economy converges to a unique stable steady state. In the left panel we have $Z_{0}^{\prime}\left(n_{0}^{*}\right) \in(0,1)$ at the initial steady state value $n_{0}^{*}$. In this case, a decrease in mobility costs implies that $n$ gradually declines from $n_{0}^{*}$ to the new steady state value $n_{1}^{*}$, i.e., emigration rises gradually over time until the economy adjusts to the new steady state. In the right panel, where $Z_{0}^{\prime}\left(n_{0}^{*}\right) \in(-1,0)$, the economy fluctuates while converging to the new steady state. In both cases, the model predicts that the steady state level of emigration rises in an economy already facing brain drain. ${ }^{15}$

\section{Government Response to Brain Drain}

Does the main theoretical prediction in Proposition 1 (higher $m$ is associated with a decrease in $w_{H}$ ) prevail if the government can respond to the productivity loss caused by higher brain drain? One obvious response would be an emigration tax (e.g., Bhagwati and Hamada, 1974; Bhagwati and Wilson, 1989). ${ }^{16}$ In our model, such a tax would

\footnotetext{
with the same rate as productivity measure $A$.

${ }^{15}$ Since $Z(0)=0$, there is also always an unstable steady state equilibrium at $n=0$, which however is economically irrelevant when starting at $n_{0}>0\left(\right.$ recall $\left.\lim _{n \rightarrow 0} Z^{\prime}(n)>1\right)$.

${ }^{16}$ See, for instance, Wildasin (2000), Andersson and Konrad (2003) and Andersen (2005) for other aspects of the question how mobility of skilled labor may change the tax system.
} 
reduce the net difference in earning opportunities for migrants, by lowering $\bar{y}$. It thus would mitigate brain drain, according to (16). Here we want to focus on an alternative policy question. We examine whether it is desirable to change the level of publicly financed investment, in order to alleviate the adverse productivity effects from higher brain drain.

We assume that an increase public spending, $G$, raises the efficiency of labor, i.e.,

$$
A=a(G)
$$

where $a^{\prime}>0, a^{\prime \prime}<0$. For instance, we may think about publicly financed infrastructure expenditure or spending for basic education. ${ }^{17}$ To simplify the analysis, we furthermore assume that emigrants still have to pay their taxes in the source country. ${ }^{18}$ Also suppose that income $\bar{y}$ of skilled emigrants is time-invariant.

We distinguish two cases. First, in the next subsection, we assume that the government faces the constraint to balance the budget. To find the optimal policy requires the definition of a government objective. We assume that the government maximizes welfare of the median voter. As emigration rates are nowhere above 50 percent, we focus on the case that the median voter is a non-migrant. Second, we allow governments to incur public debt. In this scenario, we assume that the government is not only concerned about the present generation of non-migrants but also about the public deficit, which future generations have to repay. Similarly, we capture a concern for future generations also by assuming that the level of emigration may enter the government objective, due to adverse productivity effects of emigration.

\footnotetext{
${ }^{17}$ Our formulation reflects full depreciation of public investment over time, which we assume for simplicity. According to the model, in the case of public education spending, there is literally full depreciation since individuals only work for one period and there is no intergenerational human capital transmission.

${ }^{18}$ The main insights of our analysis would not change if we assumed that emigrants do not pay taxes at home. However, there would be additional effects which complicate the analysis, since the tax base would shrink due to emigration.
} 


\subsection{Balanced Budget}

Suppose first that the government budget is balanced each period. Thus, the government budget constraint for financing public spending reads $G=\tau\left[w_{L} L+(1-e) w_{H} H\right]$. Using equilibrium conditions $w_{L}=(1-e) w_{H}$ and $H+L=1$, we have $\tau w_{H}=\frac{G}{1-e}$. Thus, after-tax wage income of a skilled non-migrant is given by

$$
\begin{aligned}
w_{H, t}^{n e t} & =w_{H, t}-\tau_{t} w_{H, t} \\
& =\gamma a\left(G_{t}\right) n_{t-1}-\frac{G_{t}}{1-e} \equiv w\left(G_{t}, n_{t-1}\right),
\end{aligned}
$$

according to (14) and (17). We find partial derivatives $w_{n}>0, w_{G G}<0, w_{G n}>$ 0 . Property $w_{n}>0$ reflects the specialization gains implied by a larger number of intermediate goods producers, discussed after Lemma 1. The property that net wage income is strictly concave as a function of $G$ (recall $a^{\prime \prime}<0$ ) ensures an interior optimal value of $G$, as will become apparent. Property $w_{G n}>0$ will be of particular importance: If net wage income declines due to a decrease of the number of firms $n$ (for instance, triggered by a reduction in mobility costs), then the marginal impact of an increase in $G$ on net wages also declines. This property is an outcome of three features of the model. First, the capital good $(X)$ is complementary to the efficiency units of labor in final goods production, according to (3). Second, the efficiency of labor, $A$, is rising in public investment, $G$, according to (17). Third, due to specialization effects the output of the capital good, $X$, depends on the number of intermediate good firms, $n$. Taken together, a higher number of firms raises the impact of an increase in public investment on wages.

It is useful to write

$$
m=\Phi\left(\frac{\bar{y}}{w_{H}^{n e t}}-1\right) \equiv \chi q\left(w_{H}^{n e t}\right)
$$

where function $q$ has support $[0, \bar{y}]$ and fulfills properties $q(\bar{y})=0, \lim _{w_{H}^{n e t} \rightarrow 0} q\left(w_{H}^{n e t}\right)=1 / \chi$, $q^{\prime}<0$ and, under (A1), $q^{\prime \prime}>0 . \chi$ is a shift parameter which reflects the degree of the integration of the market for skilled labor. That is, an increase in $\chi$ raises the number of migrants for any net wage rate $w_{H}^{\text {net }}<\bar{y}$. Using (18) and (19), the difference equation 
for the evolution of $n,(15)$, can be rewritten as

$$
n_{t}=\frac{1-e}{f}\left[1-\chi q\left(w\left(G_{t}, n_{t-1}\right)\right)\right]-\frac{1+r}{\alpha} n_{t-1} \equiv \Gamma\left(G_{t}, n_{t-1}, \chi\right)
$$

Thus, in a steady state, the number of intermediate good firms is implicitly given by

$$
n^{*}=\Gamma\left(G, n^{*}, \chi\right)
$$

as a function of $G$ and $\chi$. Note that under the assumptions of Proposition 1, there is a single interior solution of $(21)$ for any $(G, \chi)$, which we denote by function $\hat{n}(G, \chi)$. Since $\Gamma_{n}<1$ holds in a stable equilibrium (which is the case we focus on) and $\Gamma_{\chi}<0$, we have $\hat{n}_{\chi}(G, \chi)<0$; that is, labor market integration reduces the steady state number of firms for a given level of $G$, as we know already from part (ii) of Proposition 1.

Using (6) and (7), in equilibrium, welfare for all non-migrants is $v\left((1-e) w_{H}^{n e t}\right)$, which in $t$ is maximized if $w_{H, t}^{n e t}=w\left(G_{t}, n_{t-1}\right)$ is maximized. Since the number of emigrants is adversely related to the after-tax wage rate (see (19)), the government therefore aims to minimize emigration.

Suppose that initially the economy is in its steady state and the initial degree of labor market integration is represented by $\chi_{0}$. Also suppose that, in the initial period, the public investment level maximizes long run welfare. Define

$$
W(G, \chi) \equiv w(G, \hat{n}(G, \chi))
$$

Initially, the level of public investment is thus given by

$$
G_{0}^{*} \equiv \arg \max _{G} W\left(G, \chi_{0}\right)
$$

The corresponding initial number of firms is $n_{0}=\hat{n}\left(G_{0}^{*}, \chi_{0}\right)$. Since $\Gamma_{\chi}<0$, an increase in parameter $\chi$ from $\chi_{0}$ to $\chi_{1}>\chi_{0}$ (decline in mobility costs) lowers the number of firms in the next period: $n_{1}=\Gamma\left(G_{0}^{*}, n_{0}, \chi_{1}\right)<n_{0}$ (see also Fig. 1). We can show the following.

Proposition 2. Suppose (A1) holds and the government needs to balance its budget. 
When the economy is initially in a stable steady state and mobility costs decline (increase from $\chi_{0}$ to $\left.\chi_{1}>\chi_{0}\right)$, the following holds:

(i) The optimal public investment level is lower than initially both in the subsequent period after labor market integration and in the new steady state, i.e.,

$$
\begin{aligned}
& G_{0}^{*}>G_{1} \equiv \arg \max _{G} w\left(G, n_{1}\right), \\
& G_{0}^{*}>G_{1}^{*} \equiv \arg \max _{G} W\left(G, \chi_{1}\right) .
\end{aligned}
$$

(ii) Both in the subsequent period after the shift and after full adjustment to the new steady state the after-tax wage rate for skilled labor $\left(w_{H}^{\text {net }}\right)$ decreases and the number of emigrants $(m)$ increases.

Proposition 2 suggests that governments which care about non-migrants choose to lower the level of public investment when facing higher brain drain. ${ }^{19}$ The result follows because the marginal gain from public investment declines if there are less specialization gains $\left(w_{G n}>0\right)$, where the reduction in the number of intermediate good firms in source economies is induced by labor market integration. Because not only the after-tax wage rate declines but also the tax payment $(G)$ does, the gross wage rate $w_{H}$ declines as well.

We can thus conclude that, as in the basic model, declining mobility costs accentuate both migration flows and income differences among economies also when public investment spending levels adjust optimally. This holds true even with respect to wage income for skilled workers, which declines in the source economy along with higher brain drain.

We can show an additional, interesting result which highlights the role of TFP for migration patterns, where TFP depends on the number of intermediate good firms.

Corollary 1. In steady state, the optimal long run public investment level, $G^{*}$, maximizes the long run number of firms, i.e., $G^{*}=\arg \max _{G} \hat{n}(G, \chi)$.

The result shows that, in the long run, minimizing the number of emigrants via public

\footnotetext{
${ }^{19}$ The result may not hold for all periods during the transition to a new steady state, as the economy may fluctuate in the transition, as shown in panel (b) of Figure 1.
} 
investment policy is equivalent to maximizing the steady state number of firms and thus wages.

\subsection{Debt Finance}

Now we allow the government to finance public investment also by incurring a deficit. Denoting tax revenue by $T$, analogously to the previous subsection, we have $\tau w_{H}=$ $\frac{T}{1-e}$. The amount of government borrowing is $B=G-T$. Hence, $\tau w_{H}=\frac{G-B}{1-e}$ and, consequently,

$$
w_{H, t}^{n e t}=\gamma a\left(G_{t}\right) n_{t-1}-\frac{G_{t}-B_{t}}{1-e} \equiv \tilde{w}\left(G_{t}, B_{t}, n_{t-1}\right) .
$$

A higher amount of borrowing defers costs for current public investment to the future and thus raises current wage income, $\tilde{w}_{B}>0$. Similarly to the balanced budget case, we find $\tilde{w}_{n}>0, \tilde{w}_{G G}<0, \tilde{w}_{G n}>0$. Moreover, $\tilde{w}_{B n}=\tilde{w}_{B G}=\tilde{w}_{B B}=0$, i.e., the marginal impact of higher borrowing on net wage rates of non-migrants does not depend on the number of firms, the level of public investment, or the amount of borrowing.

We assume that the government care about life-time utility of non-migrants, as before. Moreover, in order to capture potential concerns about future generations, it dislikes borrowing. Possibly, it also dislikes brain drain per se. In order to capture such potential concerns about future generations formally, suppose the objective function in $t$ reads

$$
v\left((1-e) w_{H, t}^{n e t}\right)-\xi\left(m_{t}\right)-\psi\left(B_{t}\right)
$$

where $\xi^{\prime} \geq 0, \psi^{\prime}>0, \xi^{\prime \prime} \geq 0, \psi^{\prime \prime} \geq 0$ is assumed. The next proposition shows that the basic relationship between wages and migration still prevails if governments in source economies can run public debts when adjusting to declining mobility costs.

Proposition 3. Suppose (A1) holds and the government maximizes objective function (27) with respect to $(G, B) .{ }^{20}$ When the economy is initially in a stable steady state and mobility costs decline (increase from $\chi_{0}$ to $\chi_{1}>\chi_{0}$ ), the following holds:

(i) The optimal level of public investment is lower and the public deficit is higher

\footnotetext{
${ }^{20}$ Concavity of the objective function is presumed.
} 
than initially in the subsequent period after labor market integration. Long run effects on investment and deficit are ambiguous.

(ii) The result in part (ii) of Proposition 2 is maintained.

The short run effect of declining mobility costs is similar to the effect without the possibility that the government can incur a deficit (part (i)). Since the number of firms declines in an economy facing brain drain, the impact of an increase in public investment, $G$, on domestic wages declines. Analogously to the balanced budget case in the previous subsection, this follows from property $\tilde{w}_{G n}>0$. The amount of borrowing, $B$, is increasing. Intuitively, the government wants to mitigate the increased current migration pressure by reducing the tax burden.

Also in the long run the marginal impact of higher public investment on welfare again declines with further integration (see the proof of Proposition 3 on-line). Moreover, the marginal impact of higher debt on welfare increases. Formally, analogously to (22), we can express long-run welfare (27) as a function of $G, B$, and the level of labor market integration, $\chi$. Denote this function by $W(G, B, \chi)$. We show in the appendix that, as claimed, $W_{G \chi}<0$ and $W_{B \chi}>0$ hold. These effects would suggest that also in the long run non-migrants may benefit from both lower public investment and higher debt when markets for skilled labor further integrate. However, it turns out that public investment and deficits are complementary for welfare; i.e., $W_{G B}>0$. The reason is the following. A higher deficit raises the number of firms for a given public investment level, since current after-tax wage income increases. Thus, emigration incentives are mitigated. In turn, this raises the marginal impact of higher public investment on wages (since $\tilde{w}_{G n}>0$ ) and gives rise to property $W_{G B}>0$. Consequently, the total long run effect of labor market integration on both public investment and the public deficit remain ambiguous.

Most importantly, however, our main result prevails (part (ii)). Also with the possibility of adjustment of public investment policy, declining mobility costs lower wages even for skilled workers in the source country and aggravate the brain drain. The main hypothesis derived from the basic model thus seems to remain robust to responses in 
public investment policy and debt finance.

\section{Concluding Remarks}

In this paper we analyzed the dynamic interaction between migration of high-skilled workers and relative wage income between source and destination economies of expatriates. Our theoretical model showed that a decline in mobility costs not only intensifies the emigration pressure for economies already suffering from brain drain, but also adversely affects total factor productivity in the source economy. Therefore it may give rise to future emigration. The result holds true also if economies optimally adjust their productivity-enhancing public expenditure levels, possibly financed by public deficits.

Hence, our analysis suggests that integration of labor markets for high-skilled workers accentuates between-country wage income inequality. Therefore, the recent movement of the EU to attract high-skilled workers may have first-order detrimental effects even for skilled workers in developing countries. One cannot rule out, however, that countries which have seen a large outflow of skilled workers in the more recent past may benefit in the longer run from return migration, remittances, or increased education levels.

\section{References}

[1] Andersen, Torben M. (2005). Migration, taxation and educational incentives, Economics Letters 87, 399-405.

[2] Andersson, Fredrik and Kai A. Konrad (2003). Human capital investment and globalization in extortionary states, Journal of Public Economics 87, 1539-1555.

[3] Beine, Michel, Frédéric Docquier and Hillel Rapoport (2001). Brain drain and economic growth: theory and evidence, Journal of Development Economics 64, 275-89.

[4] Beine, Michel, Fréderic Docquier and Hillel Rapoport (2008). Brain drain and human capital formation in developing countries: winners and losers, Economic Journal 118, 631-652. 
[5] Bhagwati, Jagdish N. and Koichi Hamada (1974). The brain drain, international integration of markets for professionals and unemployment, Journal of Development Economics 1, 19-42.

[6] Bhagwati, Jagdish N. and John D. Wilson (1989). Income taxation and international mobility, Cambridge, MA: MIT Press.

[7] Borjas, George J. (1994). The Economics of Immigration, Journal of Economic Literature 32, 1667-1717.

[8] Borjas, George J. (2003). The Labor Demand Curve Is Downward Sloping: Reexamining the Impact of Immigration on the Labor Market, Quarterly Journal of Economics 118, 1335-1374.

[9] Card, David (2009). Immigration and Inequality, American Economic Review Papers \& Proceedings 99, 1-21.

[10] Docquier, Frédéric and Aldeslam Marfouk (2006). International migration by educational attainment (1990-2000) - Release 1.1, in: C. Ozden and M. Schiff (eds), International Migration, Remittances and Development, Palgrave Macmillan, New York.

[11] Dustmann, Christian, Francesca Fabbri and Ian Preston (2005). The Impact of Immigration on the British Labour Market, Economic Journal 115, F324-F341.

[12] Ethier, Wilfred J. (1982). National and international returns to scale in the modern theory of international trade. American Economic Review 72, 389-405.

[13] Friedberg, Rachel M. (2001). The Impact Of Mass Migration On The Israeli Labor Market, Quarterly Journal of Economics 116, 1373-1408

[14] Grogger, Jeffrey and Gordon H. Hanson (2008). Income maximization and the selection and sorting of international migrants, NBER Working Paper No. 13821. 
[15] Grossmann, Volker and David Stadelmann (2008). International mobility of the highly skilled, endogenous R\&D, and public infrastructure investment, IZA Discussion Paper No. 3366.

[16] Grossmann, Volker and David Stadelmann (2009). High-Skilled Migration and Publicly Financed Investments, University of Fribourg, mimeo.

[17] Justman, Moshe and Jacques-François Thisse (1997). Implications of the mobility of skilled labor for local public funding of higher education, Economics Letters 55, 409-412.

[18] Justman, Moshe and Jacques-François Thisse (2000). Local public funding of higher education when skilled labor is mobile, International Tax and Public Finance 7, 247258.

[19] Lucas, Robert E.B. (2005). International migration and economic development: Lessons from low-income Countries, Edward Elgar.

[20] Miyagiwa, Kaz (1991). Scale economies in education and the brain drain problem, International Economic Review 32, 743-759.

[21] Mountford, Andrew (1997). Can a brain drain be good for growth in the source economy?, Journal of Development Economics 53, 287-303.

[22] Mountford, Andrew and Hillel Rapoport (2007). The Brain Drain and the World Distribution of Income and Population, CReAM Discussion Paper No 04/07.

[23] Romer, Paul M. (1990). Endogenous Technological Change, Journal of Political Economy 98, 71-101.

[24] Stark, Oded, Christian Helmenstein and Alexia Prskawetz (1997). A brain gain with a brain drain, Economics Letters 55, 227-234.

[25] Stark, Oded, Christian Helmenstein, Alexia Prskawetz (1998). Human capital depletion, human capital formation, and migration: a blessing in a 'curse'?, Economics Letters 60, 363-367. 
[26] Wildasin, David (2000). Labor-market integration, investment in risky human capital, and fiscal competition, American Economic Review 90, 73-95.

[27] Yabuuchi, Shigemi and Sarbajit Chaudhuri (2007). International migration of labour and skilled-unskilled wage inequality in a developing economy, Economic Modelling 24, 128-137. 


\section{On-Line Appendix with Proofs for "Does International Mobility of High-Skilled Workers Aggravate Between-Country Inequality?" by Volker Grossmann and David Stadelmann}

Proof of Lemma 1. Factor prices in the final goods sector equal marginal productivities; thus, $w_{H}=\beta Y / H_{Y}$ and $w_{L}=(1-\alpha-\beta) Y / L_{Y}$. Using (7), we find that the relative input of the two types of labor in the domestic economy is independent of the level of migration:

$$
\frac{H_{Y}}{L_{Y}}=\frac{\beta(1-e)}{1-\alpha-\beta}
$$

From the inverse demand function of any intermediate good firm $j$, optimal price $p(j)=$ $r / \alpha$ and the production function in the final goods sector (3) we find

$$
x_{t-1}(j)=\left(\frac{\alpha^{2}}{(1+r) r}\right)^{\frac{1}{1-\alpha}}\left(\frac{H_{Y, t}}{L_{t, Y}}\right)^{\frac{\beta}{1-\alpha}} A_{t} L_{Y, t} \equiv \bar{x}_{t-1} .
$$

The production function for the capital good, (4), implies that $\left(X_{t}\right)^{\alpha}=n_{t-1}\left(\bar{x}_{t-1}\right)^{\alpha}$ Substituting this into (3) and using both (28) and (29) leads to

$$
Y_{t}=n_{t-1}\left(\frac{\alpha^{2}}{(1+r) r}\right)^{\frac{\alpha}{1-\alpha}}\left(\frac{\beta(1-e)}{1-\alpha-\beta}\right)^{\frac{\beta}{1-\alpha}} A_{t} L_{Y, t}
$$

Substituting (30) into $w_{L}=(1-\alpha-\beta) Y / L$ and combining the resulting expression with $w_{H}=\frac{w_{L}}{1-e}$ from (7) confirms (14).

Expression (16) follows from substituting (14) into (13) and using $w_{H}^{n e t}=(1-\tau) w_{H}$.

To confirm (15), first, insert $H=1-L$ in (12) and use both (28) and (11) to find

$$
L_{Y}=L=\frac{1-\alpha-\beta}{1-\alpha}\left(1-m-\frac{n f}{1-e}\right)
$$

Next, we employ the zero-profit condition for intermediate good firms, $\pi(j)=0$, or $(p(j)-r) x(j)=w_{H} f$, according to $(10)$. Substituting into the latter equation $p(j)=$ $r / \alpha$, the expression for $x(j)$ in (29) and the expression for $w_{H}$ in (14), as well as using 
(28) and (31) leads to

$$
\frac{\alpha(1-e)}{1+r}\left(1-m_{t}-\frac{n_{t} f}{1-e}\right)=n_{t-1} f
$$

Substituting (16) into (32) and solving for $n_{t}$ we obtain (15). From (15), it it is straightforward to derive the claimed properties of function $Z(n)$.

Proof of Proposition 1. According to Lemma 1, function $Z$ starts at zero and initially has a slope above unity which eventually turns negative. Because we know that, in addition, $Z^{\prime \prime}<0$ holds under (A1), there is a single non-zero value $n^{*}$ which fulfills $Z\left(n^{*}\right)=n^{*}$. This confirms part (i). To confirm part (ii), note from the definition of $Z$ in (15) that the value of $Z$ decreases for each $n>0$ if mobility costs decline and employ Fig. 1. Part (iii) can immediately be inferred from Fig. 1.

Proof of Proposition 2. First, note from the definition of $G_{1}$ that it is given by $w_{G}\left(G_{1}, n_{1}\right)=0$ (recall $w_{G G}<0$ ). Recalling $n_{1}<n_{0}$ and $w_{G n}>0$ confirms $(24)$.

In steady state, the first-order condition to the maximization of $W(G, \chi)$ reads

$$
\left[W_{G}(G, \chi)=\right] w_{G}(G, \hat{n}(G, \chi))+w_{n}(G, \hat{n}(G, \chi)) \hat{n}_{G}(G, \chi)=0,
$$

according to (22). Applying the implicit function theorem to (21), we obtain:

$$
\hat{n}_{G}(G, \chi)=\frac{\Gamma_{G}(G, \hat{n}, \chi)}{1-\Gamma_{n}(G, \hat{n}, \chi)} .
$$

Note that the denominator is positive in a stable steady state equilibrium $\left(\Gamma_{n}(G, \hat{n}, \chi)<\right.$ 1). Moreover, from (20) we find

$$
\Gamma_{G}(G, \hat{n}, \chi)=-\frac{1-e}{f} \chi q^{\prime}(w(G, \hat{n})) w_{G}(G, \hat{n})
$$

Substituting (34) into (33) and using (35), we can rewrite the first-order condition to

$$
w_{G}(G, \hat{n})\left[1-\frac{1-e}{f} \chi q^{\prime}(w(G, \hat{n})) \frac{w_{n}(G, \hat{n})}{1-\Gamma_{n}(G, \hat{n}, \chi)}\right]=0
$$


Define $G^{*}(\chi) \equiv \arg \max _{G} W(G, \chi)$ as the optimal log-run public investment level. Suppose that $G^{*}$ is given by first-order condition (33). (It will become apparent that the second-order condition indeed holds.) As the term in squared brackets in (36) is positive, we find that $G^{*}$ is given by

$$
w_{G}\left(G^{*}, \hat{n}\left(G^{*}, \chi\right)\right)=0
$$

Thus, we also have $\hat{n}_{G}\left(G^{*}, \chi\right)=0$, according to (34) and (35).

We next show that the second-order condition holds, i.e., $W_{G G}\left(G^{*}, \chi\right)<0$. To see this, note that $\hat{n}_{G}\left(G^{*}, \chi\right)=0$ implies that $W_{G}\left(G^{*}, \chi\right)=w_{G}\left(G^{*}, \hat{n}\left(G^{*}, \chi\right)\right)$ when $G^{*}$ is given by first-order condition (33). Hence,

$$
W_{G G}\left(G^{*}, \chi\right)=\left.\left(w_{G G}+w_{G n} \hat{n}_{G}\right)\right|_{G=G^{*}}
$$

Using again $\hat{n}_{G}\left(G^{*}, \chi\right)=0$, we thus have $W_{G G}\left(G^{*}, \chi\right)=\left.\left(w_{G G}\right)\right|_{G=G^{*}}$. Recalling that $w_{G G}<0$ confirms that the second-order condition holds.

Moreover, we have

$$
W_{G \chi}\left(G^{*}, \chi\right)=\left.\left(w_{G n} \hat{n}_{\chi}\right)\right|_{G=G^{*}}
$$

Thus,

$$
\frac{\mathrm{d} G^{*}(\chi)}{\mathrm{d} \chi}=-\frac{W_{G \chi}\left(G^{*}, \chi\right)}{W_{G G}\left(G^{*}, \chi\right)}=\left.\left(-\frac{w_{G n} \hat{n}_{\chi}}{w_{G G}}\right)\right|_{G=G^{*}}
$$

Since $w_{G G}<0, w_{G n}>0$ and $\hat{n}_{\chi}<0$, we find that $G^{*}$ is decreasing with $\chi$, which confirms (25) and concludes the proof of part (i).

To prove part (ii), recall first that $w_{n}>0$. Since public investment is chosen optimally before and after the change in the degree of labor market integration $\left(w_{G}\left(G_{1}, n_{1}\right)=\right.$ $\left.w_{G}\left(G_{0}, n_{0}\right)=0\right)$ and $n_{1}<n_{0}$, we have $w\left(G_{1}, n_{1}\right)<w\left(G_{0}, n_{0}\right)$ for the net wage rate. For the level of emigration, according to (19) and property $q^{\prime}<0$, this implies

$$
m_{1}=\chi_{1} q\left(w\left(G_{1}, n_{1}\right)\right)>\chi_{0} q\left(w\left(G_{0}, n_{0}\right)\right)=m_{0} .
$$

This confirms the result for the subsequent period after labor market integration.

Now write $G^{*}(\chi)$ as the function which is implicitly defined by $\hat{n}_{G}\left(G^{*}, \chi\right)=0$ and 
define $W^{*}(\chi) \equiv W\left(G^{*}(\chi), \chi\right) \cdot W^{*}(\chi)$ is the steady state value of the net wage rate $w_{H}^{\text {net }}$ when $G$ is chosen optimally. We find that

$$
\frac{\mathrm{d} W^{*}}{\mathrm{~d} \chi}=W_{G}\left(G^{*}, \chi\right) \frac{\mathrm{d} G^{*}}{\mathrm{~d} \chi}+W_{\chi}\left(G^{*}, \chi\right)
$$

Note that $W_{G}\left(G^{*}, \chi\right)=0$ and $W_{\chi}\left(G^{*}, \chi\right)=\left.w_{n} \hat{n}_{\chi}\right|_{G=G^{*}}<0$, where the latter is implied from using definition (22) together with $\hat{n}_{G}\left(G^{*}, \chi\right)=0$. Thus, $\mathrm{d} W^{*} / \mathrm{d} \chi<0$. Moreover, note that the steady state number of migrants is given by

$$
m^{*}(\chi) \equiv \chi q\left(W^{*}(\chi)\right)
$$

under the optimal choice of $G$. Using $q^{\prime}<0$ then implies that $m^{*}$ is increasing in $\chi$. This concludes the proof.

Proof of Corollary 1. Using (34) and (35) together with $w_{G}\left(G^{*}, \hat{n}\right)=\hat{n}_{G}\left(G^{*}, \chi\right)=$ 0 , it is easy to confirm that $\hat{n}_{G G}\left(G^{*}, \chi\right)<0$, by utilizing property $w_{G G}<0$. This shows that $G^{*}$, which is given by $(37)$, maximizes $\hat{n}(G, \chi)$.

Proof of Proposition 3. Analogously to (20), by using (26), the difference equation for the evolution of $n$ can be written as

$$
n_{t}=\frac{1-e}{f}\left[1-\chi q\left(\tilde{w}\left(G_{t}, B_{t}, n_{t-1}\right)\right)\right]-\frac{1+r}{\alpha} n_{t-1} \equiv \tilde{\Gamma}\left(G_{t}, B_{t}, n_{t-1}, \chi\right) .
$$

For a given fiscal policy, $(G, B)$, the steady state number of firms, $n^{*}$, is implicitly defined by $n^{*}=\tilde{\Gamma}\left(G, B, n^{*}, \chi\right)$, where stability requires that $\tilde{\Gamma}_{n}\left(G, B, n^{*}, \chi\right)<1 . n^{*}$ is a function of $(G, B, \chi)$ which is denoted by $\tilde{n}(G, B, \chi)$. Substituting $m=\chi q\left(w_{H}^{\text {net }}\right)$ and (26) into (27), long run welfare can be written as

$$
W(G, B, \chi) \equiv v((1-e) \tilde{w}(G, B, \tilde{n}(G, B, \chi)))-\xi(\chi q(\tilde{w}(G, B, \tilde{n}(G, B, \chi))))-\psi(B) .
$$


Since the economy is initially in a stable steady state, initially, fiscal policy is given by

$$
\left(G_{0}^{*}, B_{0}^{*}\right) \equiv \arg \max _{(G, B)} W\left(G, B, \chi_{0}\right)
$$

Thus, the initial number of firms is $n_{0}=\tilde{n}\left(G_{0}^{*}, B_{0}^{*}, \chi_{0}\right)=\tilde{\Gamma}\left(G_{0}^{*}, B_{0}^{*}, n_{0}, \chi_{0}\right)$. Moreover, if labor market integration shifts from $\chi_{0}$ to $\chi_{1}>\chi_{0}$, we have $n_{1}=\tilde{\Gamma}\left(G_{0}^{*}, B_{0}^{*}, n_{0}, \chi_{1}\right)<n_{0}$, according to (44). Also define

$$
\bar{W}(G, B, n) \equiv v((1-e) \tilde{w}(G, B, n))-\xi(\chi q(\tilde{w}(G, B, n)))-\psi(B)
$$

and

$$
\left(G_{1}, B_{1}\right) \equiv \arg \max _{(G, B)} \bar{W}\left(G, B, n_{1}\right)
$$

First-order conditions to the maximization problem in (48) are:

$$
\begin{aligned}
& \bar{W}_{G}=\left[v^{\prime}((1-e) \tilde{w})(1-e)-\xi^{\prime}(\chi q(\tilde{w})) \chi q^{\prime}(\tilde{w})\right] \tilde{w}_{G}=0, \\
& \bar{W}_{B}=\left[v^{\prime}((1-e) \tilde{w})(1-e)-\xi^{\prime}(\chi q(\tilde{w})) \chi q^{\prime}(\tilde{w})\right] \tilde{w}_{B}-\psi^{\prime}(B)=0 .
\end{aligned}
$$

Since the term in squared brackets in (49) and (50) is positive (recall $v^{\prime}>0, \xi^{\prime}>$ $\left.0, q^{\prime}<0\right)$, we have $\tilde{w}_{G}\left(G_{1}, B_{1}, n\right)=0$. Together with $\tilde{w}_{G B}=0$, we thus find that $\bar{W}_{G B}\left(G_{1}, B_{1}, n_{1}\right)=0$. Moreover, $\bar{W}_{G G}\left(G_{1}, B_{1}, n_{1}\right)<0$ and $\bar{W}_{G n}\left(G_{1}, B_{1}, n_{1}\right)>0$ since $\tilde{w}_{G G}<0$ and $\tilde{w}_{G n}>0$, respectively. Thus, $G_{1}$ is decreasing in $n_{1}$. Since $n_{1}<n_{0}$, it follows that $G_{1}<G_{0}^{*}$. Moreover, we have

$$
\begin{aligned}
& \bar{W}_{B B}=\left[(1-e)^{2} v^{\prime \prime}-\xi^{\prime \prime}(\cdot) \chi^{2} q^{\prime}-\xi^{\prime} \chi q^{\prime \prime}\right]\left(\tilde{w}_{B}\right)^{2}-\psi^{\prime \prime}<0, \\
& \bar{W}_{B n}=\left[(1-e)^{2} v^{\prime \prime}-\xi^{\prime \prime}(\cdot) \chi^{2} q^{\prime}-\xi^{\prime} \chi q^{\prime \prime}\right] \tilde{w}_{n} \tilde{w}_{B}<0
\end{aligned}
$$

(recall $\tilde{w}_{B B}=0, v^{\prime \prime}<0, \xi^{\prime \prime} \geq 0, q^{\prime \prime}>0, \psi^{\prime \prime} \geq 0$ ). Thus, $B_{1}$ is decreasing in $n_{1}$. Since $n_{1}<n_{0}$, it follows that $B_{1}>B_{0}^{*}$.

It remains to be shown that long run effects are ambiguous. The first-order conditions to the problem of maximizing long run welfare $(45)), W(G, B, \chi)$, with respect to $(G, B)$, 
are:

$$
\begin{aligned}
& W_{G}=\left[v^{\prime}((1-e) \tilde{w})(1-e)-\xi^{\prime}(\chi q(\tilde{w})) \chi q^{\prime}(\tilde{w})\right]\left(\tilde{w}_{G}+\tilde{w}_{n} \tilde{n}_{G}\right)=0, \\
& W_{B}=\left[v^{\prime}((1-e) \tilde{w})(1-e)-\xi^{\prime}(\chi q(\tilde{w})) \chi q^{\prime}(\tilde{w})\right]\left(\tilde{w}_{B}+\tilde{w}_{n} \tilde{n}_{B}\right)-\psi^{\prime}(B)=0 .
\end{aligned}
$$

According to (44), we have

$$
\tilde{n}_{G}=-\frac{\frac{1-e}{f} \chi q^{\prime}(\tilde{w}) \tilde{w}_{G}}{1-\tilde{\Gamma}_{n}} \text { and } \tilde{n}_{B}=-\frac{\frac{1-e}{f} \chi q^{\prime}(\tilde{w}) \tilde{w}_{B}}{1-\tilde{\Gamma}_{n}}>0 .
$$

The latter inequality follows from $\tilde{\Gamma}_{n}<1$ (which holds in stable steady state), $q^{\prime}<0$ and $\tilde{w}_{B}>0$. Using (55) in (53) and (54), we can write

$$
\begin{aligned}
& W_{G}=\Omega \Theta \tilde{w}_{G}=0 \\
& W_{B}=\Omega \Theta \tilde{w}_{B}-\psi^{\prime}(B)=0,
\end{aligned}
$$

where

$$
\begin{aligned}
\Omega & \left.\equiv\left[v^{\prime}((1-e) \tilde{w})(1-e)-\xi^{\prime}(\chi q(\tilde{w})) \chi q^{\prime}(\tilde{w})\right]\right|_{n=n^{*}} \\
\Theta & \left.\equiv\left(1-\frac{\frac{1-e}{f} \chi q^{\prime}(\tilde{w})}{1-\tilde{\Gamma}_{n}}\right)\right|_{n=n^{*}}
\end{aligned}
$$

Note that $\Omega>0$ and $\Theta>0$. Thus, at the optimal long run levels $\left(G^{*}, B^{*}\right)$, it holds that $\tilde{w}_{G}=\tilde{n}_{G}=0$. This implies

$$
\begin{aligned}
\left.W_{G G}\right|_{\left(G^{*}, B^{*}\right)} & =\Omega \Theta \tilde{w}_{G G}<0, \\
\left.W_{G B}\right|_{\left(G^{*}, B^{*}\right)} & =\Omega \Theta\left(\tilde{w}_{G B}+\tilde{w}_{G n} \tilde{n}_{B}\right)>0,
\end{aligned}
$$

where the inequality in (60) follows from $\tilde{w}_{G G}<0$ and the one in (61) from $\tilde{w}_{G B}=0$, $\tilde{w}_{G n}>0, \tilde{n}_{B}>0$. Moreover,

$$
\left.W_{G \chi}\right|_{\left(G^{*}, B^{*}\right)}=\Omega \Theta \tilde{w}_{G n} \tilde{n}_{\chi}<0
$$


where the inequality follows from $\tilde{w}_{G n}>0$ and

$$
\tilde{n}_{\chi}=-\frac{\frac{1-e}{f} q(\tilde{w})}{1-\tilde{\Gamma}_{n}}<0 .
$$

Next, note that

$$
\begin{aligned}
& \frac{\partial \Omega}{\partial B}=\left[(1-e)^{2} v^{\prime \prime}-\xi^{\prime \prime} \chi^{2} q^{\prime}(\cdot)^{2}-\xi^{\prime} \chi q^{\prime \prime}(\cdot)\right]\left(\tilde{w}_{B}+\tilde{w}_{n} \tilde{n}_{B}\right), \\
& \frac{\partial \Omega}{\partial \chi}=(1-e)^{2} v^{\prime \prime} \tilde{w}_{n} \tilde{n}_{\chi}-\xi^{\prime \prime} \chi q^{\prime}\left[q+\chi q^{\prime} \tilde{w}_{n} \tilde{n}_{\chi}\right]-\xi^{\prime}\left[q^{\prime}+\chi q^{\prime \prime} \tilde{w}_{n} \tilde{n}_{\chi}\right], \\
& \frac{\partial \Theta}{\partial B}=-\frac{1-e}{f} \chi \frac{q^{\prime \prime}\left(\tilde{w}_{B}+\tilde{w}_{n} \tilde{n}_{B}\right)\left(1-\tilde{\Gamma}_{n}\right)+q^{\prime}\left(\tilde{\Gamma}_{n B}+\tilde{\Gamma}_{n n} \tilde{n}_{B}\right)}{\left(1-\tilde{\Gamma}_{n}\right)^{2}}, \\
& \frac{\partial \Theta}{\partial \chi}=-\frac{1-e}{f} \frac{\left[q^{\prime}+\chi q^{\prime \prime} \tilde{w}_{n} \tilde{n}_{\chi}\right]\left(1-\tilde{\Gamma}_{n}\right)+\chi q^{\prime}\left(\tilde{\Gamma}_{n \chi}+\tilde{\Gamma}_{n n} \tilde{n}_{\chi}\right)}{\left(1-\tilde{\Gamma}_{n}\right)^{2}} .
\end{aligned}
$$

From $v^{\prime \prime}<0, \xi^{\prime \prime} \geq 0, q^{\prime}<0, \xi^{\prime} \geq 0, q^{\prime \prime}>0, \tilde{w}_{B}>0, \tilde{w}_{n}>0, \tilde{n}_{B}>0, \tilde{n}_{\chi}<0$, we find that $\partial \Omega / \partial B<0$ and $\partial \Omega / \partial \chi>0$. Moreover, using the definition of $\tilde{\Gamma}$ in (44), we have

$$
\tilde{\Gamma}_{n}=-\frac{1-e}{f} \chi q^{\prime}(\tilde{w}) \tilde{w}_{n}-\frac{1+r}{\alpha}
$$

Thus, recalling $\tilde{w}_{B}>0, \tilde{w}_{n}>0, \tilde{w}_{n n}=0, \tilde{n}_{B}>0, \tilde{n}_{\chi}<0, q^{\prime}<0, q^{\prime \prime}>0$, we find

$$
\begin{aligned}
\tilde{\Gamma}_{n B} & =-\frac{1-e}{f} \chi q^{\prime \prime}\left(\tilde{w}_{B}+\tilde{w}_{n} \tilde{n}_{B}\right)<0, \\
\tilde{\Gamma}_{n n} & =-\frac{1-e}{f} \chi\left[q^{\prime \prime}\left(\tilde{w}_{n}\right)^{2}+q^{\prime} \tilde{w}_{n n}\right]<0, \\
\tilde{\Gamma}_{n \chi} & =-\frac{1-e}{f} q^{\prime} \tilde{w}_{n}>0 .
\end{aligned}
$$

Thus, $\partial \Theta / \partial B<0$ and $\partial \Theta / \partial \chi>0$. Recalling $\tilde{w}_{B B}=\tilde{w}_{B n}=0$ and $\psi^{\prime \prime} \geq 0$, we then have

$$
\begin{aligned}
W_{B B} & =\frac{\partial \Omega}{\partial B} \Theta \tilde{w}_{B}+\Omega \frac{\partial \Theta}{\partial B} \tilde{w}_{B}+\Omega \Theta\left(\tilde{w}_{B B}+\tilde{w}_{B n} \tilde{n}_{B}\right)-\psi^{\prime \prime}(B)<0, \\
W_{B \chi} & =\frac{\partial \Omega}{\partial \chi} \Theta \tilde{w}_{B}+\Omega \frac{\partial \Theta}{\partial \chi} \tilde{w}_{B}+\Omega \Theta \tilde{w}_{B n} \tilde{n}_{\chi}>0 .
\end{aligned}
$$

Note that concavity of $W$ as a function of $(G, B)$ requires that $W_{G G} W_{B B}-\left(W_{G B}\right)^{2}>$ 
0. According to Cramer's rule, we then have

$$
\begin{aligned}
& \operatorname{sgn}\left(\frac{\mathrm{d} G^{*}}{\mathrm{~d} \chi}\right)=\left.\operatorname{sgn}\left(-W_{G \chi} W_{B B}+W_{B G} W_{B \chi}\right)\right|_{\left(G^{*}, B^{*}\right)}, \\
& \operatorname{sgn}\left(\frac{\mathrm{d} B^{*}}{\mathrm{~d} \chi}\right)=\left.\operatorname{sgn}\left(-W_{G G} W_{B \chi}+W_{G B} W_{G \chi}\right)\right|_{\left(G^{*}, B^{*}\right)} .
\end{aligned}
$$

Thus, using the previous results on the signs of the second derivatives on the right hand sides of (73) and (74) confirms that long run effects of labor market integration on fiscal variables are ambiguous. This confirms part (i).

To prove part (ii), first note that analogously to the proof of part (ii) of Proposition 2, $n_{1}<n_{0}$ implies that $w_{H}^{\text {net }}$ declines and $m$ increases in the period subsequent to labor market integration. To show the result for the steady state, define $W^{*}(\chi) \equiv$ $W\left(G^{*}(\chi), B^{*}(\chi), \chi\right)$. We find that

$$
\frac{\mathrm{d} W^{*}}{\mathrm{~d} \chi}=W_{G}\left(G^{*}, B^{*}, \chi\right) \frac{\mathrm{d} G^{*}}{\mathrm{~d} \chi}+W_{B}\left(G^{*}, B^{*}, \chi\right) \frac{\mathrm{d} B^{*}}{\mathrm{~d} \chi}+W_{\chi}\left(G^{*}, B^{*}, \chi\right),
$$

where $W_{G}=W_{B}=0$ at $\left(G^{*}, B^{*}\right)$ and, according to (45),

$$
W_{\chi}=(1-e) v^{\prime} \tilde{w}_{n} \tilde{n}_{\chi}-\xi^{\prime}\left[q+\chi q^{\prime} \tilde{w}_{n} \tilde{n}_{\chi}\right]<0 .
$$

Thus, $\mathrm{d} W^{*} / \mathrm{d} \chi<0$. Analogously to the proof of Proposition 2, together with (43) for the steady state level of migration, this concludes the proof. 